\title{
Short Communication \\ Risks of second primary cancer among patients with major histological types of lung cancers in both men and women
}

\section{S-C Chuang ${ }^{1,2}$, G Scélo', Y-CA Lee ${ }^{1,3}$, S Friis ${ }^{4}$, E Pukkala ${ }^{5}$, DH Brewster ${ }^{6}$, K Hemminki ${ }^{7,8}$, E Tracey9, E Weiderpass $10,11,12,13$, S Tamaro' ${ }^{14}$, V Pompe-Kirn ${ }^{15}$, EV Kliewer ${ }^{14,16,17}$, K-S Chia ${ }^{16,18}$, JM Tonita ${ }^{19,20}$, C Martos' ${ }^{21}$, JG Jonasson ${ }^{22,23}$, P Boffetta ${ }^{1,24,25}$, P Brennan' and M Hashibe ${ }^{*, 1,26}$}

IInternational Agency for Research on Cancer (IARC), Lyon, France; '2Department of Epidemiology and Biostatistics, School of Public Health, Imperial College London, London, UK; ${ }^{3}$ Department of Epidemiology, School of Public Health, University of California, Los Angeles, CA, USA; ${ }^{4}$ Institute of Cancer Epidemiology, Danish Cancer Society, Copenhagen, Denmark; ${ }^{5}$ Finnish Cancer Registry, Institute for Statistical and Epidemiology Cancer Research, Helsinki, Finland; ${ }^{6}$ Scottish Cancer Registry, Information Services, NHS National Services Scotland, Edinburgh, Scotland, UK; ' Division of Molecular Genetic Epidemiology, German Cancer Research Center (DKFZ). Heidelberg, Germany; ${ }^{8}$ Center for Family and Community Medicine, Karolinska Institutet, Huddinge, Sweden; ${ }^{9}$ New South Wales Cancer Registry, Eveleigh, New South Wales, Australia; ${ }^{10}$ The Cancer Registry of Norway, Oslo, Norway; 1 'Department of Community Medicine, University of Tromso, Tromso, Norway; ${ }^{2}$ Department of Medical Epidemiology and Biostatistics, Karolinska Institutet, Stockholm, Sweden; ${ }^{13}$ Department of Genetic Epidemiology, Samfundet Folkhalsan, Helsinki, Finland; ${ }^{14}$ British Columbia Cancer Agency, Vancouver, British Columbia, Canada; ${ }^{15}$ Cancer Registry of Slovenia, Institute of Oncology, Ljubljana, Slovenia; ${ }^{16}$ Epidemiology and Cancer Registry, CancerCare Manitoba, Winnipeg, Manibota, Canada; ${ }^{17}$ Department of Community Health Sciences, University of Manitoba, Winnipeg, Manibota, Canada; ${ }^{18}$ Center for Molecular Epidemiology, Singapore; ${ }^{19}$ Singapore Cancer Registry, Singapore; ${ }^{20}$ Saskatchewan Cancer Agency, Regina, Saskatchewan, Canada; ${ }^{21}$ Cancer Registry of Zaragoza, Aragon Health Science Institute, Zaragoza, Spain; ${ }^{22}$ Icelandic Cancer Registry, Icelandic Cancer Society, Reykjavik, Iceland; ${ }^{23}$ Faculty of Medicine, University of Iceland, Reykjavik, Iceland; ${ }^{24}$ The Tisch Cancer Institute, Mount Sinai School of Medicine, New York, NY, USA; ${ }^{25}$ International Prevention Research Institute, Lyon, France; ${ }^{26}$ University of Utah School of Medicine, Salt Lake City, UT, USA

BACKGROUND: Patterns of second primary cancers (SPCs) following first primary lung cancers (FPLCs) may provide aetiological insights into FPLC.

METHODS: Cases of FPLCs in 13 cancer registries in Europe, Australia, Canada, and Singapore were followed up from the date of FPLC diagnosis to the date of SPC diagnosis, date of death, or end of follow-up. Standardised incidence ratios (SIRs) were calculated to estimate the magnitude of SPC development following squamous cell carcinoma (SCC), small cell lung carcinoma (SCLC), and adenocarcinoma (ADC).

RESULTS: Among SCC patients, male SIR $=1.58$ (95\% confidence interval $(\mathrm{Cl})=1.50-1.66)$ and female $\mathrm{SIR}=2.3 \mathrm{I}(\mathrm{I} .94-2.72)$ for smoking-related SPC. Among SCLC patients, the respective ratios were $1.39(1.20-1.60)$ and 2.28 (I.73-2.95), and among ADC patients, they were $1.73(1.57-1.90)$ and $2.24(1.91-2.61)$. We also observed associations between first primary lung ADC and second primary breast cancer in women $(\mathrm{SIR}=1.25,95 \% \mathrm{Cl}=1.05-1.48)$ and prostate cancer $(1.56,1.39-1.79)$ in men.

CONCLUSION: The FPLC patients carried excess risks of smoking-related SPCs. An association between first primary lung ADC and second primary breast and ovarian cancer in women at younger age and prostate cancers in men may reflect an aetiological role of hormones in lung ADC.

British Journal of Cancer (2010) 1 02, I190- I 195. doi:I0.1038/sj.bjc.66056I6 www.bjcancer.com

(c) 2010 Cancer Research UK

Keywords: lung cancer; SPCs; sex differences

Lung cancer is the most common cancer in the world, representing $12.4 \%$ of all new cancer cases in the year 2002 (Parkin et al, 2005), its main risk factor being tobacco smoking. Other risk factors are involuntary smoking and occupational exposure to agents such as asbestos, radon, arsenic, and silica dust; suspected risk factors include air pollution and dietary factors, notably low

*Correspondence: Dr M Hashibe, Division of Public Health, Department of Family \& Preventive Medicine, University of Utah School of Medicine, 375 Chipeta Way, Suite A, Salt Lake City, UT, 84I08, USA;

E-mail: Mia.Hashibe@utah.edu

Received 30 October 2009; revised 20 January 2010; accepted 22 February 2010 consumption of fruits and vegetables (Teppo et al, 2001; Spitz et al, 2006; World Cancer Research Fund, 2007).

There are four major lung cancer subtypes: squamous cell carcinoma (SCC), large cell carcinoma, adenocarcinoma (ADC), and small cell lung carcinoma (SCLC), comprising over $90 \%$ of all cases (Spitz et al, 2006). Although smoking is associated with all histological types of lung cancer, ADC has a weaker association with smoking than other types in terms of smoking status, intensity, duration, age at start, dose, and years since quitting (Barbone et al, 1997).

Several studies examined second primary cancers (SPCs) following lung cancer (Levi et al, 1999; Teppo et al, 2001; Liu et al, 2002; Duchateau and Stokkel, 2005), but not by gender. As lung cancer epidemiology is different in men and women, 
aetiology may also differ and be reflected in SPCs. This study includes three major histological types of lung cancer: SCC, SCLC, and ADC. We have examined differences in the pattern of SPCs between men and women who had a first primary lung cancer (FPLCs).

\section{MATERIALS AND METHODS}

An international multicentre study was initiated to incorporate large cancer registries that have been in operation for at least 25 years, to conduct a systematic analysis of SPCs (Brennan et al, 2005; Scelo et al, 2006). The registries included New South Wales in Australia, British Columbia, Manitoba and Saskatchewan in Canada, Denmark, Finland, Iceland, Norway, Scotland, Singapore, Slovenia, Sweden, and Zaragoza in Spain. These registries had cancer data covering different time periods within the period 1943-2000. A high degree of ascertainment completeness by the registry is suggested by consistent inclusion in subsequent volumes of Cancer Incidence in Five Continents (Parkin et al, 2002).

Data were provided by each cancer registry on all first primary cancers, including age and sex of each subject, diagnosis and date of the first primary cancer, follow-up for mortality, and diagnosis and date of the SPCs, if any. In this study, any different cancer codes used by registries were systematically converted into International Classification of Disease, Ninth Revision (ICD-9). We analysed the occurrence of SPC in survivors of lung cancer (ICD-9: 162). Coding of multiple primaries in the cancer registries followed a common set of rules proposed by the International Association of Cancer Registries and the International Agency for Research on Cancer (IARC) (Muir and Percy, 1991). These define primary cancer as one that originates in a primary site or tissue and is thus neither an extension nor a recurrence nor a metastasis. Only one tumour was recognised as arising in an organ or pair of organs or tissue as defined by the three-character category of the ICD or the topography of the ICD-O. Non-melanoma skin cancer (ICD-9: 173) was excluded because of the inconsistency in reporting across registries. We defined smoking-related cancers according to the most recent IARC monograph on the subject as cancers of the lip (ICD-9: 140), tongue (141), salivary gland (142), mouth (143-145), oropharynx (146), nasopharynx (147), hypopharynx (148), pharynx unspecified (149), oesophagus (150), stomach (151), liver (155), pancreas (157), nose and nasal cavity (160), larynx (161), bladder (188), and kidney (189), and as leukaemia (204-208) (IARC Working Group, 2004).

All cases of FPLC were followed up from the date of the first lung cancer diagnosis $(1943-2000)$ to the date of SPC (1943-2000), date of death, or end of follow-up (1992-2000). To assess the potential excess occurrence of SPC, the numbers of SPCs observed and expected were used to estimate the standardised incidence ratios (SIRs). The SIRs adjusted for age, sex, year, and registry were calculated using indirect standardisation methods (Brennan et al, 2005). The expected number was calculated from accumulated person-years and age-, sex-, and calendar period-specific cancer incidence rates in each of the cancer registries.

Table I Descriptive characteristics of first primary lung cancer patients from 13 cancer registries

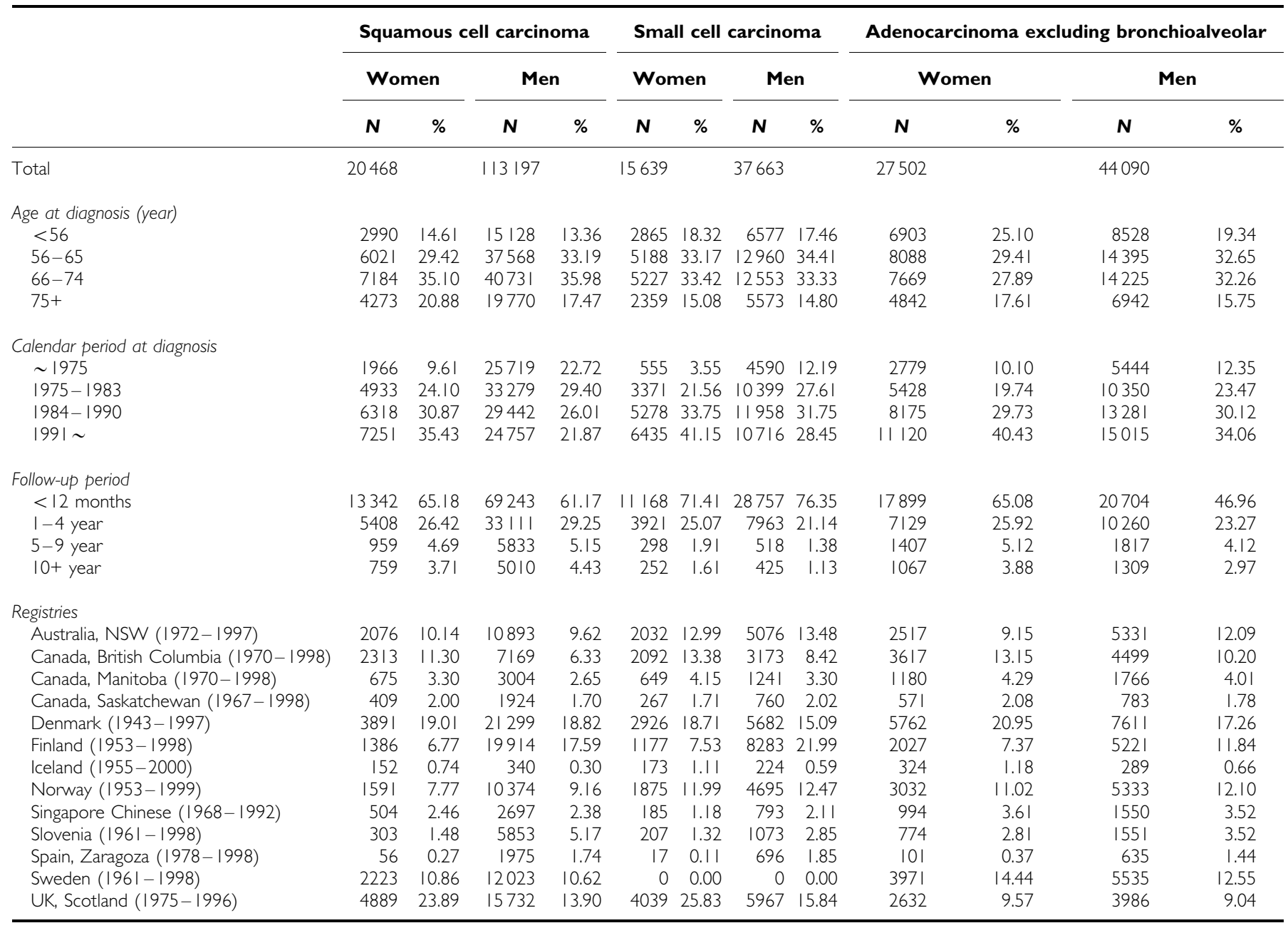


We used Poisson regression to model the observed and expected number and estimate the gender effect on SIRs (Richiardi et al, 2007). The cumulative risk of second smoking- or non-smokingrelated cancers was calculated by taking into account death as a competing risk (Gooley et al, 1999). The absolute excess risk (AER) - a measure for estimating the absolute burden or magnitude of a health problem - was defined as the difference between the observed and expected number of SPCs divided by the total number of person-years at risk, and is expressed as per 100000 person-years (Travis, 2006).

\section{RESULTS}

Table 1 summarises the characteristics of patients with a primary lung cancer by histology. A total of 63609 females with 100036 person-years of observation and 194950 males with 311666 person-years of observation were identified across the 13 cancer registries. The mean follow-up periods were 1.6 years for both men and women. During the follow-up, a total of 5383 SPCs were recorded. Among the 258559 lung cancers, 3259 SCCs (2.4\%), 557 SCLCs (1.0\%), and 1567 ADCs (2.2\%) developed an SPC, indicating an excess risk of SPCs of $36 \%$ for women and $25 \%$ for men (data not shown).

Table 2 shows the SIR and AER of the selected SPCs by sex and histology. The detailed SIRs for each SPC site and by histology are listed in Appendix Table A1. The SIRs for smoking-related second cancers were $2.31(95 \%$ confidence interval $(\mathrm{CI})=1.94-2.72)$ for female and $1.58(95 \% \mathrm{CI}=1.50-1.66)$ for male SCC patients; 2.28 $(95 \% \mathrm{CI}=1.73-2.95)$ for female and $1.39(95 \% \mathrm{CI}=1.20-1.60)$ for male SCLC patients; and $2.24(95 \% \mathrm{CI}=1.91-2.61)$ for female and $1.73(95 \% \mathrm{CI}=1.57-1.90)$ for male ADC patients. In addition to the relative measures, the absolute measure, AERs, were higher in smoking-related cancers than in non-smoking-related cancers in SCC and SCLC, whereas the burden was almost the same in ADC. Associations with second primary breast cancer $(\mathrm{SIR}=1.25,95 \%$ $\mathrm{CI}=1.05-1.48)$ among women, prostate cancer (SIR $=1.56,95 \%$ $\mathrm{CI}=1.39-1.79)$ among men, and second primary thyroid cancer among both men $(\mathrm{SIR}=3.43,95 \% \mathrm{CI}=1.57-8.62)$ and women $(\mathrm{SIR}=4.87,95 \% \mathrm{CI}=2.88-7.69)$ were observed after first primary lung ADC ( $P$-value for heterogeneity among three histological types $<0.05)$; such associations were not observed for lung SCC and SCLC.

Figure 1 shows the observed cumulative risk for smoking- and non-smoking-related SPCs by sex and histology, taking death into

Table 2 Numbers of cases (Obs), standardised incidence ratio (SIR) and absolute excess risk (AER) per 100000 person-years of selected second primary cancers after lung cancer by sex and histology

\begin{tabular}{|c|c|c|c|c|c|c|c|c|c|c|c|c|}
\hline \multirow[b]{2}{*}{ Cancer sites (ICD 9th revision) } & \multicolumn{4}{|c|}{$\begin{array}{l}\text { Squamous cell } \\
\text { carcinoma }\end{array}$} & \multicolumn{4}{|c|}{$\begin{array}{l}\text { Small cell } \\
\text { carcinoma }\end{array}$} & \multicolumn{4}{|c|}{$\begin{array}{c}\text { Adenocarcinoma excluding } \\
\text { bronchioalveolar }\end{array}$} \\
\hline & Obs & SIR & $95 \% \mathrm{Cl}$ & AER & Obs & SIR & $95 \% \mathrm{Cl}$ & AER & Obs & SIR & $95 \% \mathrm{Cl}$ & AER \\
\hline Women & \multicolumn{4}{|c|}{$P Y=34344$} & \multicolumn{4}{|c|}{$P Y=16763$} & \multicolumn{4}{|c|}{$P Y=48929$} \\
\hline All but non-melanoma skin & 377 & 1.28 & $(1.16-1.42)$ & 242.55 & 149 & $1.16^{\circ}$ & $(0.98-1.36)$ & 119.65 & 555 & 1.49 & $(1.37-1.62)$ & 374.30 \\
\hline Smoking-related cancers & 142 & 2.31 & $(1.94-2.72)$ & 234.27 & 58 & 2.28 & $(1.73-2.95)$ & 194.47 & 164 & 2.24 & $(1.91-2.61)$ & 185.80 \\
\hline Head and neck & 31 & 5.69 & $(3.87-8.08)$ & 74.41 & 9 & 3.49 & $(1.59-6.63)$ & 38.31 & 13 & 1.85 & $(0.99-3.17)$ & 12.23 \\
\hline Leukaemias (204-208) & 9 & 1.28 & $(0.58-2.42)$ & 5.73 & 9 & 3.06 & $(1.40-5.82)$ & 36.14 & 22 & 2.50 & $(1.57-3.79)$ & 27.00 \\
\hline Other smoking-related cancers & 37 & 1.94 & $(1.36-2.67)$ & 52.14 & 10 & 1.45 & $(0.70-2.67)$ & 8.58 & 41 & 1.93 & $(1.38-2.62)$ & 40.34 \\
\hline Colorectal $(153,154)$ & 41 & 0.84 & $(0.60-1.14)$ & -22.74 & 14 & 0.67 & $(0.36-1.12)$ & -41.14 & 74 & 1.26 & $(0.99-1.58)$ & 31.21 \\
\hline Colon (153) & 30 & 0.90 & $(0.61-1.29)$ & -9.71 & 9 & 0.63 & $(0.29-1.19)$ & -31.53 & 56 & 1.43 & $(1.08-1.86)$ & 34.42 \\
\hline Rectum (I54) & 11 & 0.70 & $(0.35-1.24)$ & -13.73 & 5 & 0.75 & $(0.24-1.74)$ & -9.94 & 18 & 0.93 & $(0.55-1.46)$ & -2.77 \\
\hline Non-smoking-related cancer & 194 & 1.06 & $(0.91-1.22)$ & 31.03 & 77 & 0.93 & $(0.74-1.16)$ & -33.66 & 317 & 1.32 & $(1.18-1.47)$ & 157.14 \\
\hline Female breast (174) & 87 & 1.09 & $(0.88-1.35)$ & 20.92 & 29 & 0.77 & $(0.52-1.11)$ & -51.68 & 135 & 1.25 & $(1.05-1.48)$ & 55.12 \\
\hline Men & \multicolumn{4}{|c|}{$P Y=212428$} & \multicolumn{4}{|c|}{$\mathbf{P Y}=34293$} & \multicolumn{4}{|c|}{$P Y=64945$} \\
\hline All but non-melanoma skin & 2882 & 1.21 & $(1.16-1.25)$ & 231.99 & 408 & 1.16 & $(1.05-1.27)$ & 160.26 & 1012 & $1.47^{\circ}$ & $(1.38-1.56)$ & 498.00 \\
\hline Smoking-related cancers & 1454 & 1.58 & $(1.50-1.66)$ & 250.63 & 186 & 1.39 & $(1.20-1.60)$ & 151.44 & 428 & 1.73 & $(1.57-1.90)$ & 277.11 \\
\hline Head and neck & 340 & 2.53 & $(2.27-2.8 I)$ & 96.76 & 33 & 1.50 & $(1.04-2.11)$ & 32.26 & 77 & 2.01 & $(1.59-2.51)$ & 59.57 \\
\hline Oesophagus (150) & 93 & 1.78 & $(1.44-2.18)$ & 19.18 & 12 & 1.46 & $(0.75-2.55)$ & 11.03 & 27 & 1.91 & $(1.26-3.09)$ & 19.76 \\
\hline Bladder and kidney & 565 & 1.87 & $(1.72-2.03)$ & 123.83 & 70 & 1.62 & $(1.26-2.04)$ & 77.98 & 159 & 1.90 & $(1.62-2.22)$ & 116.16 \\
\hline Leukaemias (204-208) & 74 & 0.98 & $(0.77-1.23)$ & $-0.7 \mid$ & 14 & 1.29 & $(0.7 \mid-2.17)$ & 9.18 & 33 & 1.58 & $(1.09-2.37)$ & 18.62 \\
\hline Other smoking-related cancers & 382 & 1.07 & $(0.96-1.18)$ & 11.56 & 57 & 1.14 & $(0.87-1.48)$ & 21.01 & 132 & 1.45 & $(1.21-1.72)$ & 62.99 \\
\hline Colorectal $(153,154)$ & 395 & 1.01 & $(0.92-1.12)$ & 1.84 & 46 & 0.79 & $(0.58-1.05)$ & -35.66 & 129 & 1.15 & $(0.96-1.38)$ & 25.91 \\
\hline Colon (153) & 223 & 1.00 & $(0.87-1.14)$ & 0.00 & 29 & 0.85 & $(0.57-1.22)$ & -14.92 & 81 & 1.24 & $(0.98-1.57)$ & 24.14 \\
\hline Rectum (154) & 172 & 1.04 & $(0.89-1.21)$ & 3.11 & 17 & 0.70 & $(0.41-1.13)$ & -21.25 & 48 & 1.02 & $(0.76-1.36)$ & 1.45 \\
\hline Non-smoking-related cancer & 1033 & 0.96 & $(0.90-1.02)$ & -20.48 & 176 & 1.09 & $(1.21-1.58)$ & 44.48 & 455 & 1.39 & $(1.26-1.52)$ & 195.41 \\
\hline
\end{tabular}

Abbreviations: $\mathrm{Cl}=$ confidence interval; ICD = International Classification of Disease; Obs=observed number; PY = person-years. Smoking-related cancers included: head and neck (ICD-9: lip: 140, tongue: I4I, mouth: 143- 145, oropharynx: 146, hypopharynx: I48, pharynx unspecified: |49, and larynx: 161), salivary gland (I42), nasopharynx (147), oesophagus (I50), nose and nasal cavity (160), stomach (I5I), liver (155), and pancreas (I57), bladder and kidney (I88 I89), leukaemia (204-208). AER is expressed as per 100000 . 
A

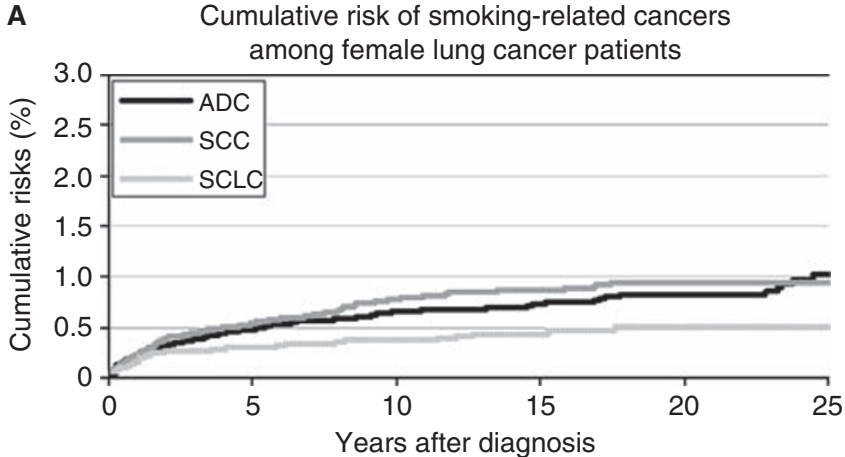

C

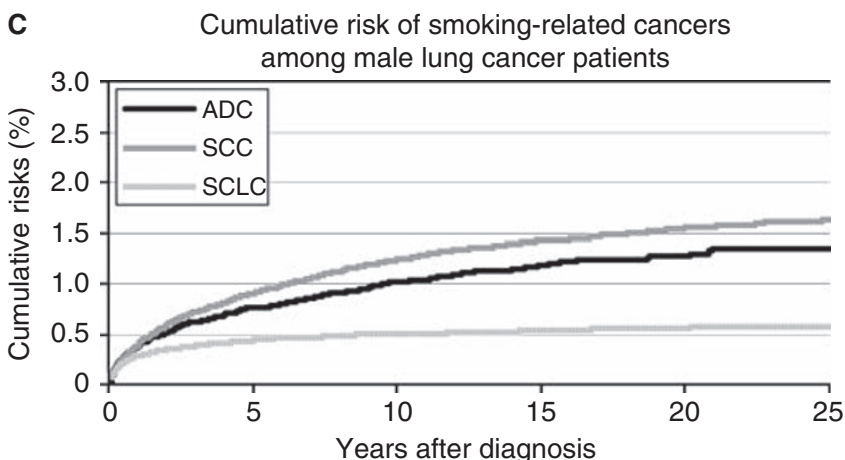

B

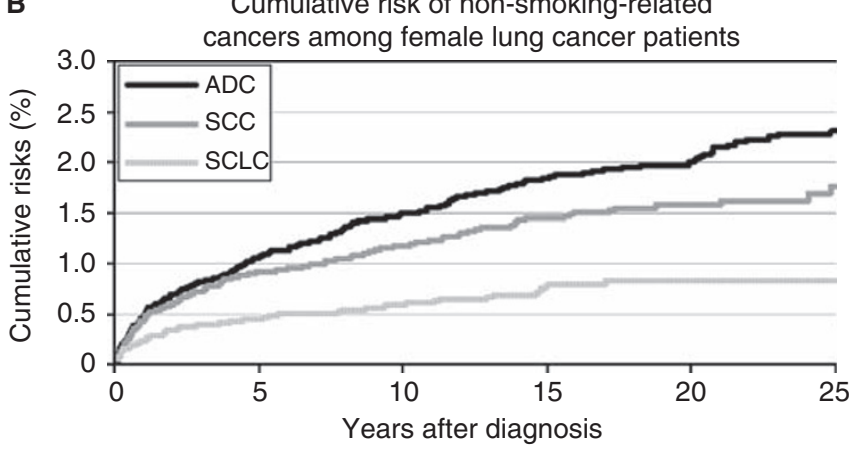

D Cumulative risk of non-smoking-related

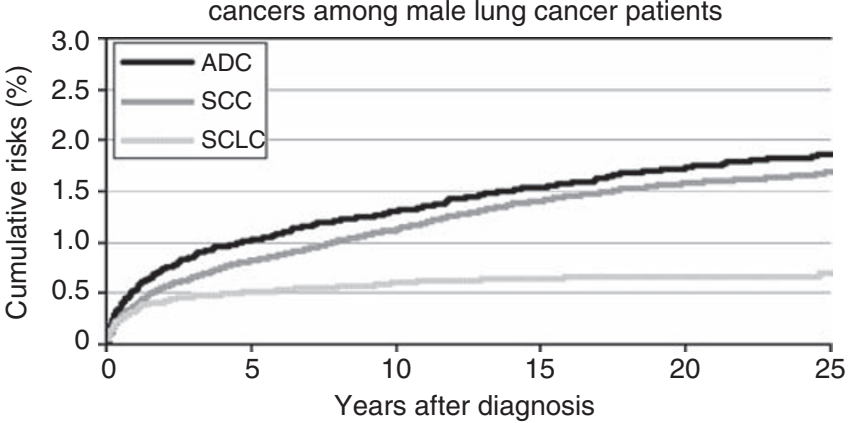

Figure I Cumulative risks of selected second primary cancer following a first primary lung cancer, taking death into account as the competing risk. ADC, adenocarcinoma; SCC, squamous cell lung carcinoma; SCLC, small cell carcinoma. A: smoking-related SPCs among female patients; B: non-smoking-related SPCs among female patients; C: smoking-related SPCs among male patients; $\mathbf{D}$ : non-smoking-related SPCs among male patients.
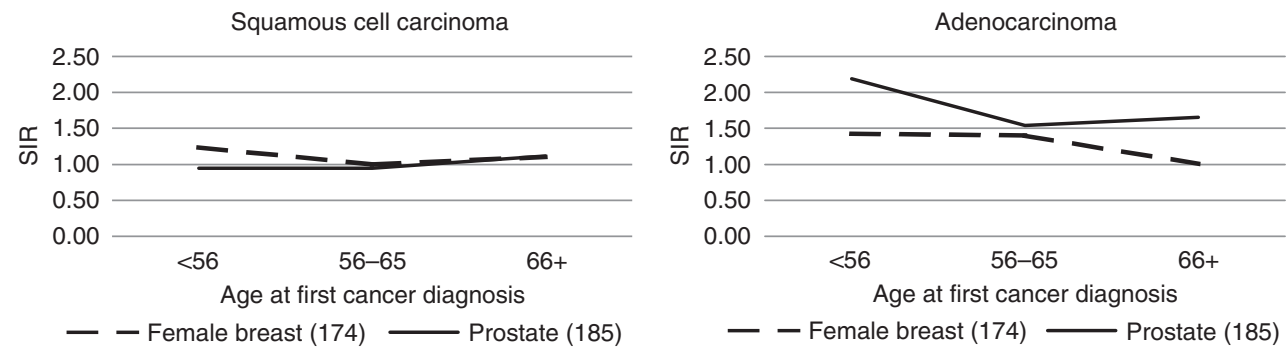

Figure 2 Standardised incidence ratios (SIRs) of second primary breast cancer in women and prostate cancer in men by age at diagnosis of first primary lung adenocarcinoma and squamous cell carcinoma.

account as a competing risk. The censored and event numbers are presented in Appendix Table A2. The 25-year cumulative risks among SCLC patients were low: among women, $0.51 \%$ developed smoking-related SPCs and $0.84 \%$ developed nonsmoking-related SPCs; among men, the rates were 0.58 and $0.70 \%$, respectively. Among SCC and ADC cases, men had higher smoking-related SPC risk than women: $1.64 \%(95 \% \mathrm{CI}=$ $1.54-1.73)$ vs $0.96 \%(95 \% \mathrm{CI}=0.78-1.13)$ among SCC patients and $1.35 \%(95 \% \mathrm{CI}=1.21-1.50)$ vs $1.02 \%(95 \% \mathrm{CI}=0.80-1.24)$ among ADC patients. In terms of non-smoking-related SPCs, women and men had similar 25-year cumulative risks $(1.77 \%, 95 \%$ $\mathrm{CI}=1.46-2.08$ for women and $1.69 \%, 95 \% \mathrm{CI}=1.60-1.79$ for men) among SCC cases, but women had a higher cumulative risk among $\mathrm{ADC}$ cases $(2.32 \%, 95 \% \mathrm{CI}=2.03-2.60$ for women and $1.87 \%, 95 \% \mathrm{CI}=1.69-2.05$ for men).

Figure 2 presents the SIRs of second primary female breast and prostate cancer by age at diagnosis of the first primary lung $\mathrm{ADC}$ and SCC. We observed associations with second primary breast cancer for those whose first primary lung ADC was diagnosed at younger age $(\mathrm{SIR}=1.43,95 \% \mathrm{CI}=1.03-1.92$ for
$<56$ years of age; and $\mathrm{SIR}=1.40,95 \% \mathrm{CI}=1.04-1.84$ for 56-65 years of age). Such an association was not observed among cases of first primary lung SCC. The associations between ADC and second primary prostate cancer were present in all age strata but decreased slightly in the older age groups. There were similar associations with ovarian cancer for women diagnosed with first primary lung ADC below 56 years of age (observed $N=12$, SIR $=2.25,95 \% \mathrm{CI}=1.16-3.94)$; second primary testicular cancer was associated with first primary lung ADC only among those who were 56-65 years of age at first cancer registration (observed $N=3$ ).

Appendix Table A3 lists SIRs for selected SPCs by calendar period and histology. Overall, the SIRs for smoking-related SPCs for women were $2.33(95 \% \mathrm{CI}=1.73-3.07)$ before $1975,2.37(95 \%$ $\mathrm{CI}=1.94-2.86)$ between 1975 and $1983,2.35(95 \% \mathrm{CI}=1.95-2.81)$ between 1984 and 1990, and $2.03(95 \% \mathrm{CI}=1.62-2.52)$ after 1990; the corresponding SIRs within the same calendar period for men were $1.44(95 \% \mathrm{CI}=1.31-1.58), 1.59(95 \% \mathrm{CI}=1.47-1.71)$, $1.63(95 \% \mathrm{CI}=1.40-1.77)$, and $1.72(95 \% \mathrm{CI}=1.55-1.91)$, respectively. 


\section{DISCUSSION}

In our study, $2 \%$ of individuals with primary lung cancer developed an SPC during a mean follow-up period of 1.6 years, representing excess risks of $36 \%$ for women and $25 \%$ for men. Overall, we observed excess risks of smoking-related SPCs for both genders in all three histological types of FPLC, as well as some types of non-smoking-related SPCs with first primary lung ADC.

The relative excess risks of smoking-related cancers after lung cancer were stronger in women than in men. Although lung cancer incidence is increasing in women, incidence rates of most smoking-related cancers are lower in women than in men. For example, the incidence rate per 100000 of head and neck cancer in the year 2002 was 15.3 in men and 4.6 in women (Ferlay et al, 2004), the difference reflecting the lower incidence of primary smoking-related cancers in women in the reference general population; comparison of AERs shows a larger AER in men.

We observed associations between smoking-related SPCs and first primary lung SCC and SCLC for both men and women. For ADC, associations were observed not only with smoking-related cancers but also with other cancers. ADC accounted for $31-54 \%$ of lung cancers among male non-smokers and for $49-74 \%$ of lung cancers among female non-smokers in North America (Charloux et al, 1997), implying the involvement of non-smoking factors in its aetiology. We observed increased SIRs for second primary female breast and ovarian cancer after lung ADC to be more pronounced among young women. Such an association was not noted in first primary lung SCC and SCLC; in men, an association between prostate and lung ADC was also observed. Because breast, ovary, and prostate cancers are hormone-related cancers, hormone-related factors may have a role in lung ADC aetiology.

A negative association between endometrial cancer and lung SCC and SCLC was observed (but not with lung ADC) (Table 2), which is consistent with its inverse association with cigarette smoking but positive association with oestrogens (Cook et al, 2006). Although IARC has reclassified colorectal cancer as being smoking related (Secretan et al, 2009), no association was observed between first primary lung and second primary colorectal cancers. Given the long induction period of smoking in colorectal carcinogenesis and the decreased risk after the cessation of smoking (Secretan et al, 2009), and the fact that quitting smoking is usual among lung cancer patients, this was expected. However, in contrast to most of the studies (Liang et al, 2009) that found a stronger association with smoking in rectal than in colon cancers, we observed an association between lung ADC and colon cancer, but not with rectal cancer. Smoking has been consistently associated with colorectal adenomatous polyps, a precancerous lesion of colorectal cancer (Botteri et al, 2008), which might suggest that ADCs share common risk factors. Nevertheless, such a pattern was not observed in the association between lung ADC and oesophageal ADC.

\section{REFERENCES}

Barbone F, Bovenzi M, Cavallieri F, Stanta G (1997) Cigarette smoking and histologic type of lung cancer in men. Chest 112(6): 1474-1479

Botteri E, Iodice S, Raimondi S, Maisonneuve P, Lowenfels AB (2008) Cigarette smoking and adenomatous polyps: a meta-analysis. Gastroenterology 134(2): $388-395$

Brennan P, Scelo G, Hemminki K, Mellemkjaer L, Tracey E, Andersen A, Brewster DH, Pukkala E, McBride ML, Kliewer EV, Tonita JM, Seow A, Pompe-Kirn V, Martos C, Jonasson JG, Colin D, Boffetta P (2005) Second primary cancers among 109000 cases of non-Hodgkin's lymphoma. Br J Cancer 93(1): 159-166

Charloux A, Quoix E, Wolkove N, Small D, Pauli G, Kreisman H (1997) The increasing incidence of lung adenocarcinoma: reality or artefact?
In our study, the SIRs for smoking-related SPCs after a first primary SCC and SCLC did not change significantly across the calendar years, but we observed an increasing trend for overall smoking-related SPCs in male ADC patients $(P$ for trend $=0.04)$, suggesting a time trend between tobacco smoking and a more important role in the development of ADC; this was not observed in female ADC cases $(P=0.74)$.

The median life expectancy in untreated SCLC is about 6 to 12 weeks (Schiller, 2002). In our study, $75 \%$ of SCLC patients were followed up for less than 1 year and the main reason for terminating follow-up was death $(97 \%)$. Fortunately, the large sample size across the registries enabled us to explore the SPCs for SCLC survivors who showed an excess risk for smoking-related, but not for non-smoking-related, cancers.

A major limitation of our study is the lack of individual-based smoking information. On the assumption that multiple cancers share risk factors, we separated smoking and non-smoking-related SPCs to examine the potential importance of smoking on male and female SPC development. We could not exclude the possibility of misclassification between metastasis and second primaries because we did not have relevant pathological information. However, our data were from high-quality cancer registries, $85 \%$ or over being microscopically verified (Parkin et al, 2002). In addition, the stratified analysis by follow-up years (data not shown) showed relatively stable SIRs across all strata. We surmised that the probability of an SPC being a metastasis would decrease with longer follow-up time. Individuals with FPLC may have increased surveillance for other smoking-related cancers, but the increased risks of non-smoking-related sites may reflect a more general surveillance bias. The large size of our study provided precision in stratified analyses.

In conclusion, SCC, SCLC, and ADC were associated with smoking-related SPCs in both men and women. Associations of ADC in female patients at younger age with second primary breast and ovarian cancers and of ADC in male patients with prostate cancer may reflect a role of hormones in lung ADC aetiology.

\section{ACKNOWLEDGEMENTS}

This work was supported by grant R03 CA101442 from the National Cancer Institute of the US NIH and by funding from the European Union, in the framework of the Public Health Programme (under the project 'Women in Europe Against Lung Cancer and Smoking' (WELAS)). Ghislaine Scelo, Yuan-Chin Amy Lee, and Shu-Chun Chuang worked on this study during the tenure of a Special Training Award from the International Agency for Research on Cancer.

Supplementary Information accompanies the paper on British Journal of Cancer website (http://www.nature.com/bjc)
A review of the epidemiology of lung adenocarcinoma. Int J Epidemiol 26(1): $14-23$

Cook LS, Weiss NS, Doherty JA, Chen C (2006) Endometrial cancer. In Cancer Epidemiology and Prevention Schottenfeld D, Fraumeni JF Jr (eds), pp 1027-1043. Oxford University Press Inc.: New York

Duchateau CS, Stokkel MP (2005) Second primary tumors involving non-small cell lung cancer: prevalence and its influence on survival. Chest 127(4): $1152-1158$

Ferlay J, Bray F, Pisani P, Parkin DM (2004) Globcan 2002: Cancer Incidence, Mortality, and Prevalence Worldwide. IARC Cancer Base No. 5[2]. IARC Press: Lyon, France. Ref Type: Computer Program 
Gooley TA, Leisenring W, Crowley J, Storer BE (1999) Estimation of failure probabilities in the presence of competing risks: new representations of old estimators. Stat Med 18(6): 695-706

IARC Working Group (2004) Tobacco smoke and involuntary smoking. IARC Monograph on the Evaluation of Carcinogenic Risks to Humans 83: 1-1438. Ref Type: Serial (Book, Monograph)

Levi F, Randimbison L, Te VC, La Vecchia C (1999) Second primary cancers in patients with lung carcinoma. Cancer 86(1): 186-190

Liang PS, Chen TY, Giovannucci E (2009) Cigarette smoking and colorectal cancer incidence and mortality: systematic review and meta-analysis. Int J Cancer 124(10): 2406-2415

Liu YY, Chen YM, Yen SH, Tsai CM, Perng RP (2002) Multiple primary malignancies involving lung cancer-clinical characteristics and prognosis. Lung Cancer 35(2): 189-194

Muir CS, Percy C (1991) Classification and coding for neoplasms. In Cancer Registration: Principles and Methods Jensen OM, Parkin DM, MacLennan R, Muir CS, Skeet RG (eds), pp 64-81. IARC: Lyon

Parkin DM, Bray F, Ferlay J, Pisani P (2005) Global cancer statistics, 2002. CA Cancer J Clin 55(2): 74-108

Parkin DM, Whelan SL, Ferlay J, Teppo L, Thomas DB (2002) Cancer Incidence in Five Continents. Vol. III. IARC: Lyon

Richiardi L, Scelo G, Boffetta P, Hemminki K, Pukkala E, Olsen JH, Weiderpass E, Tracey E, Brewster DH, McBride ML, Kliewer EV, Tonita JM, Pompe-Kirn V, Kee-Seng C, Jonasson JG, Martos C, Brennan P (2007) Second malignancies among survivors of germ-cell testicular cancer: a pooled analysis between 13 cancer registries. Int J Cancer 120(3): $623-631$

Scelo G, Boffetta P, Hemminki K, Pukkala E, Olsen JH, Andersen A, Tracey E, Brewster DH, McBride ML, Kliewer EV, Tonita JM, Pompe-Kirn V, Chia KS, Jonasson JG, Martos C, Colin D, Brennan P (2006) Associations between small intestine cancer and other primary cancers: an international population-based study. Int J Cancer 118(1): 189- 196

Schiller JH (2002) Small cell lung cancer: defining a role for emerging platinum drugs. Oncology 63(2): 105-114

Secretan B, Straif K, Baan R, Grosse Y, El GF, Bouvard V, brahim-Tallaa L, Guha N, Freeman C, Galichet L, Cogliano V (2009) A review of human carcinogens - Part E: tobacco, areca nut, alcohol, coal smoke, and salted fish. Lancet Oncol 10(11): 1033-1034

Spitz MR, Wu X, Wilkinson A, Wei Q (2006) Cancer of the Lung. In Cancer Epidemiology and Prevention Schottenfeld D, Fraumeni JF Jr (eds), pp 638-658. Oxford University Press Inc.: New York

Teppo L, Salminen E, Pukkala E (2001) Risk of a new primary cancer among patients with lung cancer of different histological types. Eur $J$ Cancer 37(5): $613-619$

Travis LB (2006) The epidemiology of second primary cancers. Cancer Epidemiol Biomarkers Prev 15(11): $2020-2026$

World Cancer Research Fund (2007) Lung. In Food, Nutrition, Physical Activity, and the Prevention of Cancer: a Global Perspective World Cancer Research Fund (ed), pp 259-264. World Cancer Research Fund/ American Institute for Cancer Research: Washington DC 